\title{
Universal balancing method of flying capacitor converters
}

\author{
Jiří Brychcín \\ Research and Innovation Centre for \\ Electrical Engineering (RICE) \\ University of West Bohemia \\ Pilsen, Czech Republic \\ brychj@fel.zcu.cz
}

\author{
Tomáš Košan \\ Research and Innovation Centre for \\ Electrical Engineering (RICE) \\ University of West Bohemia \\ Pilsen, Czech Republic \\ kosan@fel.zcu.cz
}

\author{
Zdeněk Peroutka \\ Research and Innovation Centre for \\ Electrical Engineering (RICE) \\ University of West Bohemia \\ Pilsen, Czech Republic \\ peroutka@ieee.org
}

\begin{abstract}
This paper describes novel method of balancing of multi-level flying capacitor converters. The proposed balancing block is placed behind PWM modulator instead of balancing table and it is independent on type of modulator nor number of levels. The method was simulated in ModelSIM and PLECS/Simulink and implemented in VHDL to FPGA. Function of the proposed algorithm was verified on the real seven level flying capacitor converter with three phase asynchronous machine.
\end{abstract}

Keywords-modulator, balancing, model, simulation, implementation, multilevel, flying, capacitor

\section{INTRODUCTION}

There are a lot of methods how to modulate and to balance the flying capacitor converter. Basic types of modulators are phase-shifted PWM (PSPWM), phase-disposition PWM (PDPWM), space vector PWM, together with modulators based on prediction and fuzzy logic. All these methods must be able to balance voltage on flying capacitors to achieve proper function of converter.

The most common methods for balancing voltage on flying capacitors are those with PI controllers of voltage [1], which change modulation signal or carrier signal for each transistor. They are usually followed by PSPWM modulator which has auto-balancing capability. This method is perfect for easy change of number of levels, but algorithm must be able to detect load mode (generator or motor). This problem was solved in [2], in this paper authors deal with modified PSPWM with PI controllers and they used direction of the load current in balancing block to achieve proper balancing. Another method for balancing of 4L converter is in [3], where there is proposed 4L PDPWM modulator with balancing table placed behind the modulator. There is problem with balancing table that is composed of combinatoric logic and is usable only for four level FLC converter. Any change in number of levels means redesign of balancing table. Other methods do not use triangular carrier signal, which is replaced by: space vector PWM in [4], predictive control in [5], fuzzy logic controller in [6]. These methods can be difficult to implement and can consume high amount of computation time. Also for different number of levels there is necessary to alter core algorithm and add or remove extended switching states. These problems are solved in proposed balancing algorithm based on mathematical model of FLC.

All of methods mentioned above has its advantages and disadvantages and our proposed balancing method for flying capacitor-based converters is simple and efficient replacement for them. Main advantage (universality) of our method is its independency on modulator type. This method is easy reconfigurable for required account of levels.

\section{MATHEMATICAL MODEL OF 7L FLC CONVERTER}

The power circuit of the 7L FLC is shown in Fig. 1. It was used to derive a mathematical model. There are Tx transistors and complementary transistors Tx'. Following text assumes that the positive phase current flows out of the converter to the load.

If the $\mathrm{T}_{\mathrm{XN}}$ transistor is on and its neighbor $\mathrm{T}_{\mathrm{XN}-1}$ transistor is off, the phase current will flow through the $\mathrm{C}_{\mathrm{XN}}$ capacitor and positive amplitude will discharge capacitor, negative amplitude will charge the capacitor and the $\mathrm{T}_{\mathrm{XN}}$ adds to the phase voltage value of voltage of this capacitor. If the $T_{X N}$ transistor is off and $\mathrm{T}_{\mathrm{XN}-1}$ transistor is on, the phase current will flow through the capacitor and positive amplitude of phase current will charge the $\mathrm{C}_{\mathrm{XN}}$ capacitor, negative amplitude will discharge the capacitor and the $\mathrm{T}_{\mathrm{XN}}$ ' adds to the phase voltage negative value of this capacitor voltage. If the $T_{X N}$ and $T_{X N-1}$ are both on or off, the capacitor current will be zero because it is clamped and value of the capacitor between these transistors will not influence the phase voltage. Phase voltage and polarity of flying capacitors currents were obtained in mathematical model and the phase current is calculated from known RL parameters of the load. The knowledge of phase current is necessary to determine capacitor currents, which are used for calculation of voltage of the flying capacitors. The diagram of the mathematical model of 7L FLC is shown in Fig. 2.

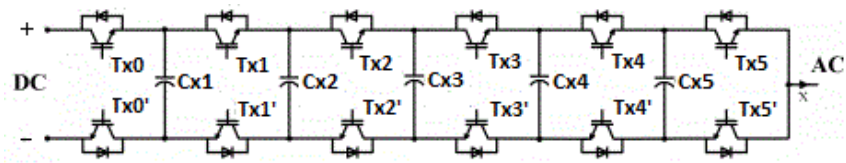

Fig. 1. Power circuit of one phase of 7L FLC

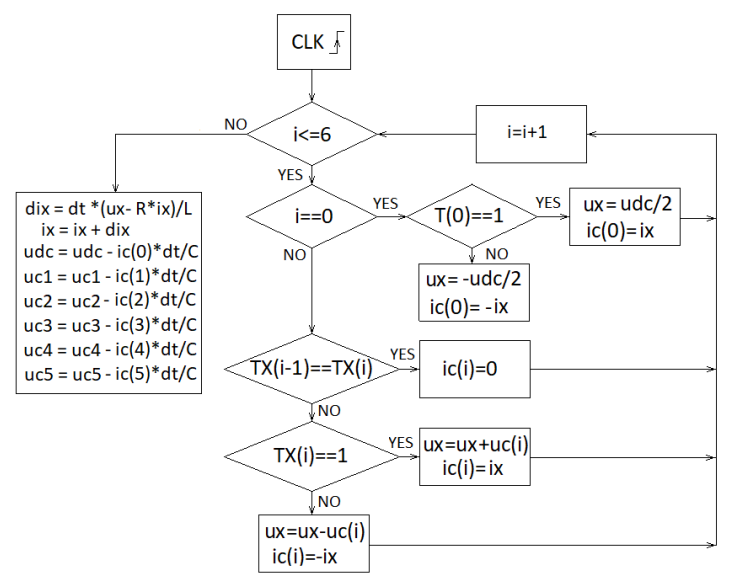

Fig. 2. Mathematical model of one phase of 7L FLC 


\section{BALANCING METHOD}

The balancing method is derived from mathematical model of 7L FLC converter, which is shown in Fig. 2. The balancing algorithm function can be divided to two steps: 1) predictor and 2) corrector. The predictor chooses the optimal switching combination according measured and required values of flying capacitors and according to the output current polarity. switching combination is chosen independently of outputs of modulator. The second step is correction of predicted switching combination. It is necessary because the output level of the balancing block has to be the same as required level, i.e. it must match output of the modulator in term of output voltage. This method uses the fact, that sum of states of upper $T_{X}$ transistors is level of output voltage. The corrector algorithm reads states of transistors in for cycle and changes the state of transistors to achieve correct value of level on output. When equality of the input and output levels is achieved, then the corrected switching combination is written to the outputs. A block diagram of the predictor is shown in Fig. 3 and corrector in Fig. 4, where $i x$ is phase current, $i$ and $x$ are pointers of array, $U c w$ is array of required values of flying capacitors voltage, $U c$ is array of values of flying capacitors voltage, $T$ is array of input signals from modulator, $T X$ is array of outputs used for balancing. The $T X$ array is written to the outputs at the end of corrector algorithm run.

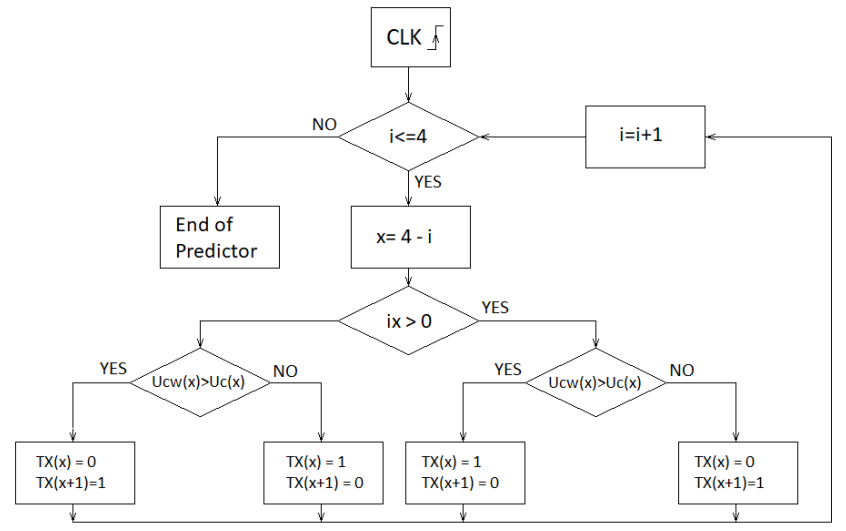

Fig. 3. Diagram of predictor function

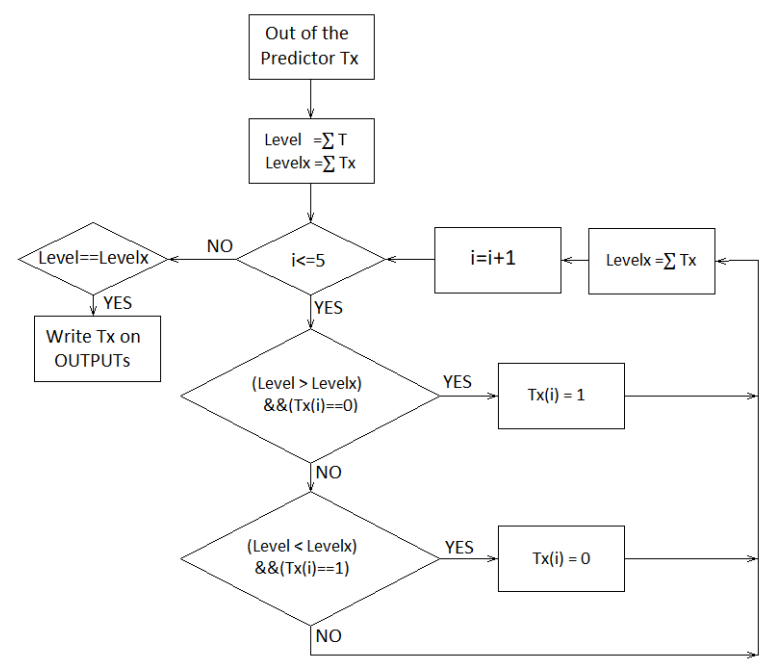

\section{VHDL SIMULATION IN MODELSIM}

VHDL simulation in ModelSIM of 7L FLC converter was performed to verify correct function of proposed balancing algorithm. The structure of VHDL entities is shown in Fig. 5. There is three phase sinus generator, followed by PWM modulator. It generates 6 output signals per each phase. These signals are then connected to the balancing entities, which choose optimal switching combination according to balancing method algorithm described in Section III. Output signals of the balancing entities are connected to the mathematical model of 7L FLC converter. The 7L FLC model is composed of three entities, one phase model of 7L FLC converter is used per each phase. Their outputs are values of flying capacitors and output phase voltages, which are calculated according to phase currents and switching combination. The mathematical model entities contain comparators, which compare whether the required values of flying capacitors are higher or lower than calculated value of flying capacitor. The outputs of comparators are connected to the balancing entities. Phase currents are calculated by last block which simulates three phase R-L load. The calculated currents are connected to the balancing and mathematical model entities. The model runs at clock frequency of $10 \mathrm{MHz}$ and the values of the voltage and currents are read by balancing entities only once per switching period of modulator. This is necessary to have the same output switching frequency as modulator frequency.

Simulation results are shown in Fig. 6, Fig. 7, Fig. 8 and Fig. 9. In Fig. 6 there is steady state of 3 phase converter voltage and first phase current for $\mathrm{R}=2 \Omega$ and $\mathrm{L}=20 \mathrm{mH}$. In Fig. 7 there is shown first phase converter voltage and first phase current during transition change of resistance, that was decreased from $120 \Omega$ to $2 \Omega$ in time $25 \mathrm{~ms}$ and in Fig. 8 is shown increase of resistance in time $75 \mathrm{~ms}$ back to $120 \Omega$, inductance was constant $\mathrm{L}=20 \mathrm{mH}$. Fig. 9 shows balancing of FLC during transition of resistance in time $25 \mathrm{~ms}$ and $75 \mathrm{~ms}$. Simulation parameters are shown in TABLE I.

TABLE I. SIMULATON PARAMETERS

\begin{tabular}{|l|l|}
\hline $\mathrm{Udc}$ & $600 \mathrm{~V}$ \\
\hline fs switching frequency & $15 \mathrm{kHz}$ \\
\hline Cx flying capacitors & $100 \mu \mathrm{F}$ \\
\hline L inductance of load & $20 \mathrm{mH}$ \\
\hline R resistance of load & $2 \Omega$ and $120 \Omega$ \\
\hline
\end{tabular}

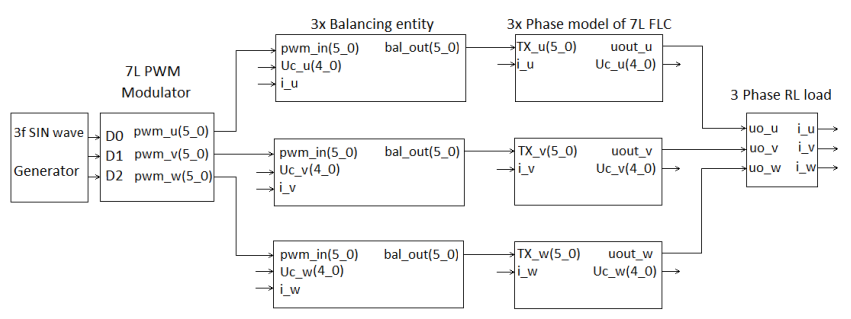

Fig. 5. Structure of implementation in VHDL

Fig. 4. Diagram of corrector function 


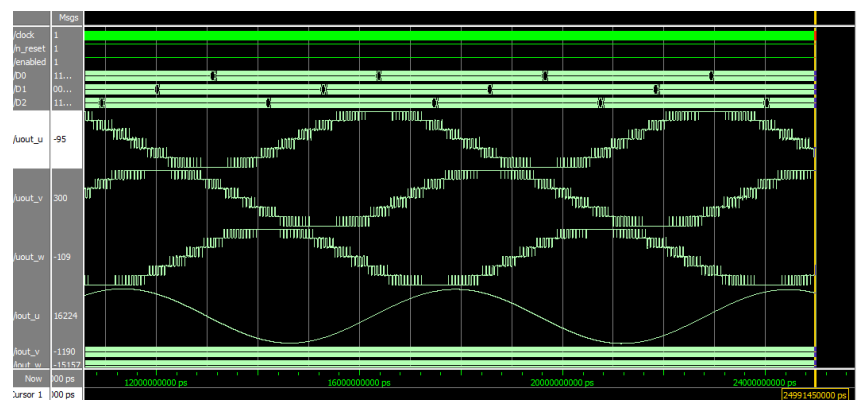

Fig. 6. 7L FLC converter 3 phase voltage and phase current - steady state for $\mathrm{R}=2 \Omega \mathrm{L}=20 \mathrm{mH}$

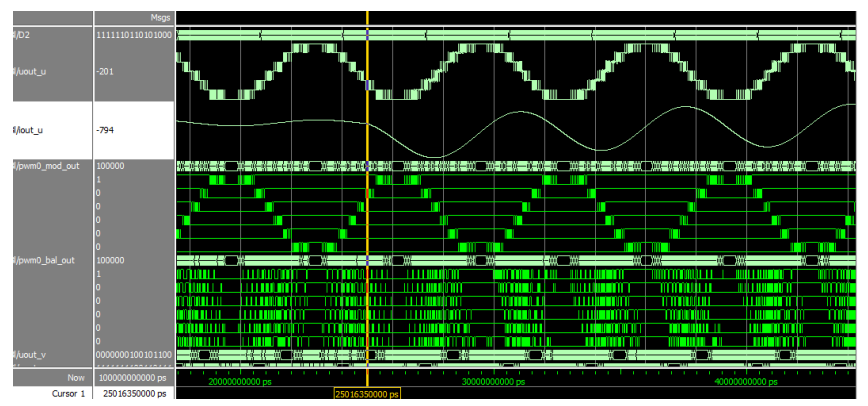

Fig. 7. Phase voltage, phase current and states of outputs of the modulator and of ouputs ofthe balancing block during transition decrease of resistance in time $25 \mathrm{~ms}$

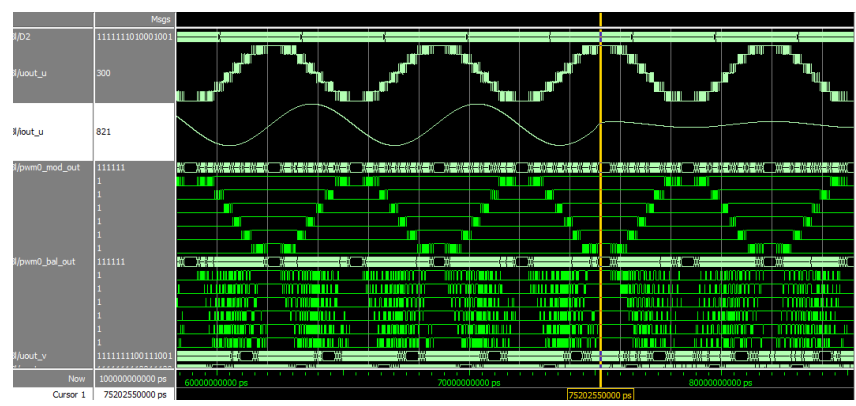

Fig. 8. Phase voltage, phase current and state of outputs of the modulator and of ouputs ofthe balancing block during transition increase of resistance int time $75 \mathrm{~ms}$

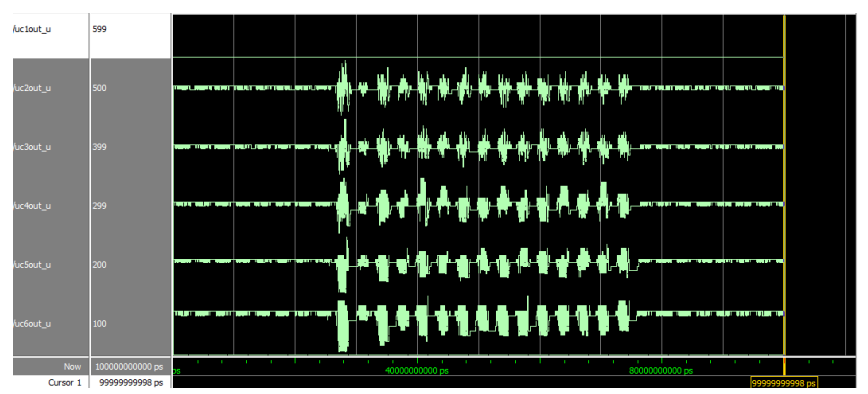

Fig. 9. Balancing of flying capacitors in transition change of resistance

\section{Simulation In PLECS/SimULinK}

For the verification of the 7L FLC balancing in VHDL, the simulation in PLECS was done for the same parameters as in ModelSIM simulation. Simulation results for steady state are in Fig. 10, transient change of resistance and balancing of flying capacitors are shown in Fig. 11. Simulation parameters are shown in TABLE I. Simulation was performed by $150 \mathrm{~Hz}$ output frequency and full amplitude of modulation signal. The maximum ripple of voltage of flying capacitors is $20 \mathrm{~V} \mathrm{p}-\mathrm{p}$. From both simulations results the proper function of balancing method is verified.
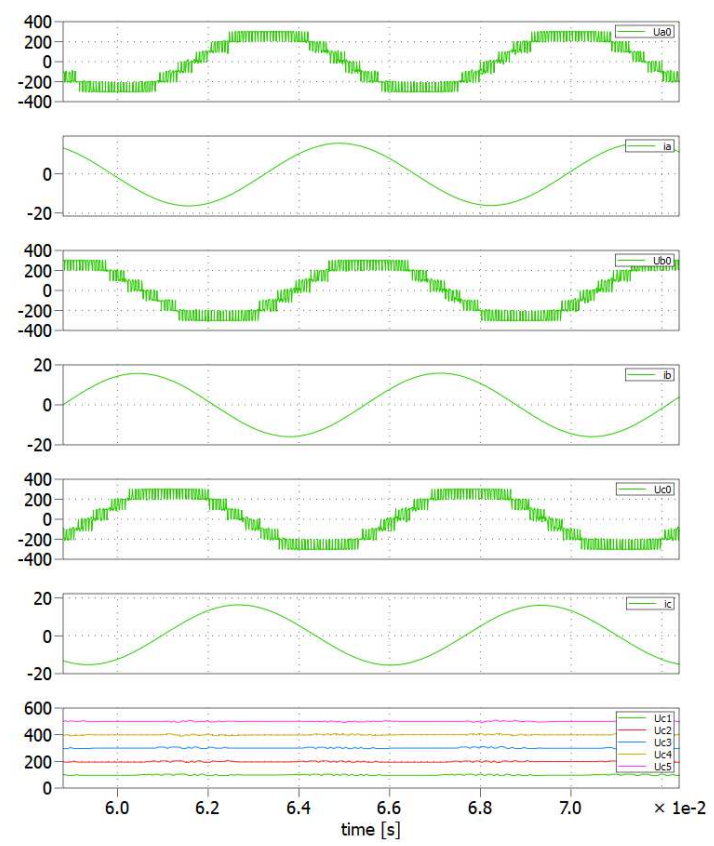

Fig. 10. 7LFLC phase converter voltage, phasecurrents and voltage of flying capacitors in steady state for $R=2 \Omega, L=20 \mathrm{mH}$
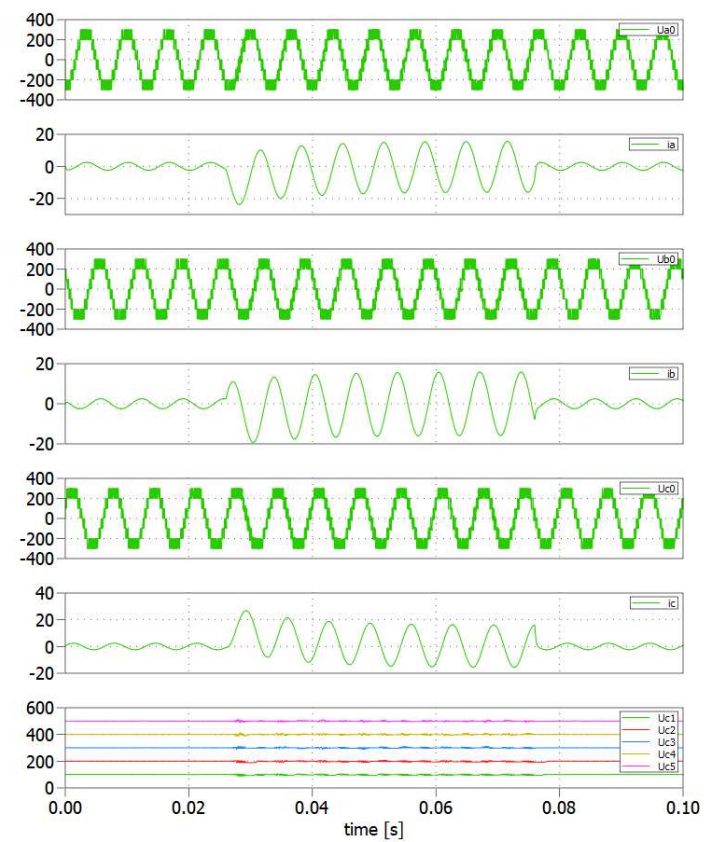

Fig. 11. 7LFLC phase converter voltage, phasecurrents and voltage of flying capacitors in transient change of resistance in time $25 \mathrm{~ms}$ and $75 \mathrm{~ms}$

\section{EXPERIMENTAL RESULTS}

For verification proposed balancing algorithm, the experiments were performed on real hardware. The hardware consists of control unit MLC interface and modular three phase 7L-FLC converter (Fig. 12). The FLC converter is loaded with three phase asynchronous machine. The MLC interface is hardware development kit with MCU module and FPGA on main board. It is equipped with DSC TMS320F28335 and FPGA EP3C40 together with AD, DA converters and up to 48 PWM outputs for multi-level converters control. The DSC is calculating three phase modulation signals and transfers them to the FPGA design. The proposed balancing algorithm is implemented in FPGA together with PD-PWM based modulator. The converter parameters are shown in TABLE II. Experimental results are 
shown in Fig. 13 and Fig. 14. Fig. 13 shows steady state for $5 \mathrm{~Hz}$ output frequency and output voltage amplitude 0.25 . Maximum voltage ripple is $10 \mathrm{~V}$ p-p. Fig. 14 shows steady state for $50 \mathrm{~Hz}$ output frequency and output voltage amplitude 1.0. Maximum voltage ripple is $10 \mathrm{~V}$ p-p. Both results show acceptable behavior of proposed balancing algorithm.

TABLE II. FLC CONVERTER AND MOTOR PARAMETERS

\begin{tabular}{|l|l|}
\hline Udc & $60 \mathrm{~V}$ \\
\hline fs switching frequency & $40 \mathrm{kHz}$ \\
\hline Cx flying capacitors & $40 \mu \mathrm{F}$ \\
\hline Rs stator resistance & $1.86 \Omega$ \\
\hline Rr rotor resistance & $1.53 \Omega$ \\
\hline Lss stator stray inductance & $5.3 \mathrm{mH}$ \\
\hline Lrs rotor stray inductance & $4.3 \mathrm{mH}$ \\
\hline Lm main inductance & $33 \mathrm{mH}$ \\
\hline J moment of inertia & $0.01 \mathrm{~kg}^{2}$ \\
\hline
\end{tabular}

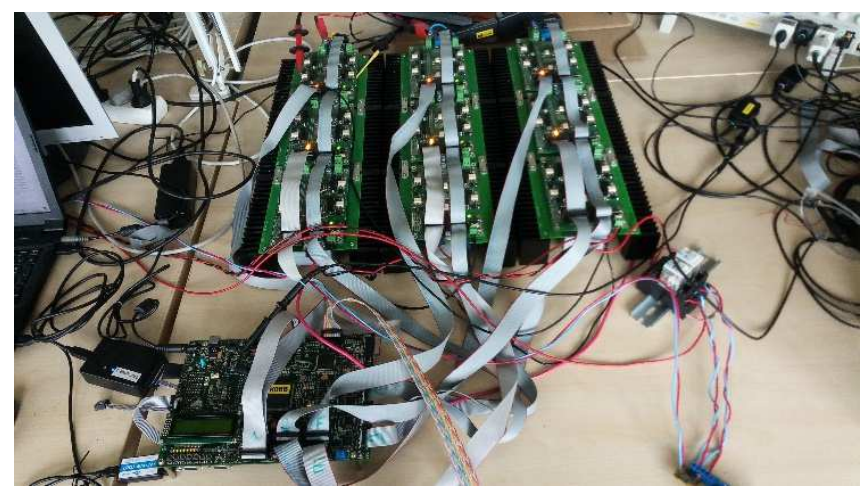

Fig. 12. MLC interface with 3 phase 7L- FLC converter

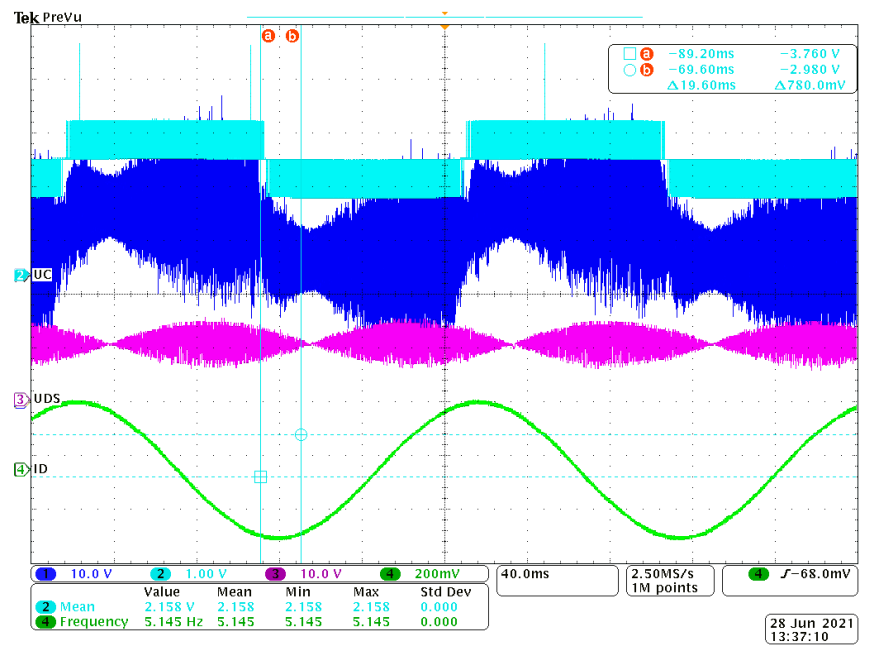

Fig. 13. Measured results for $5 \mathrm{~Hz}$ frequency : $\mathrm{CH} 1$ (blue) phase converter voltage [10V/div], $\mathrm{CH} 2$ (cyan) required level of the converter, $\mathrm{CH} 3$ (magenta) voltage of flying capacitor $\mathrm{Cx} 5[10 \mathrm{~V} / \mathrm{div}], \mathrm{CH} 4$ (green) phase current $[2 \mathrm{~A} / \mathrm{div}]$

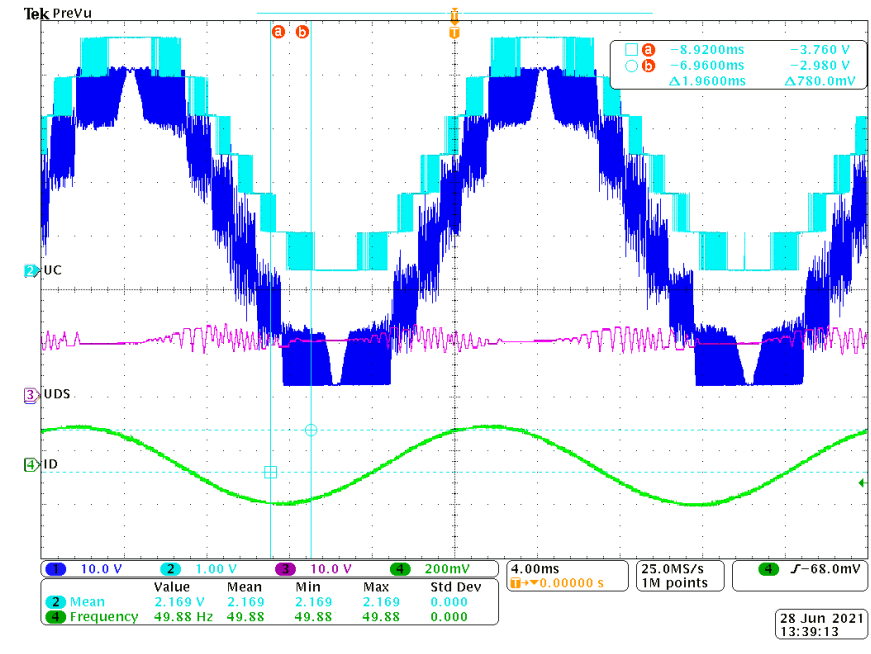

Fig. 14. Measured results for $50 \mathrm{~Hz}$ frequency : $\mathrm{CH} 1$ (blue) phase converter voltage $[10 \mathrm{~V} / \mathrm{div}], \mathrm{CH} 2$ (cyan) required level of the converter, $\mathrm{CH} 3$ (magenta) voltage of flying capacitor $\mathrm{Cx} 5[10 \mathrm{~V} / \mathrm{div}], \mathrm{CH} 4$ (green) phase current [2AV/div]

\section{CONCLUSION}

This paper describes proposed algorithm of balancing multilevel FLC converters. The balancing algorithm was simulated on 3 phase seven level FLC converter in ModelSIM and PLECS with identical results. Behavior of balancing algorithm was verified on the real three phase 7L-FLC converter with three phase asynchronous machine. The performed experiments show proper function of balancing algorithm in steady-state. Next step will be performing experiments in dynamic states and full DC-link voltage.

\section{ACKNOWLEDGMENT}

This research has been supported by the Ministry of Education, Youth and Sports of the Czech Republic under the RICE - Student Grant System SGS-2021-021.

\section{REFERENCES}

[1] M. Khazraei, H. Sepahvand, K. Corzine and M. Ferdowsi, "A generalized capacitor voltage balancing scheme for flying capacitor multilevel converters," 2010 Twenty-Fifth Annual IEEE Applied Power Electronics Conference and Exposition (APEC), Palm Springs, CA, USA, 2010, pp. 58-62, doi: 10.1109/APEC.2010.5433693.

[2] C. Feng, J. Liang and V. G. Agelidis, "Modified Phase-Shifted PWM Control for Flying Capacitor Multilevel Converters," in IEEE Transactions on Power Electronics, vol. 22, no. 1, pp. 178-185, Jan. 2007, doi: 10.1109/TPEL.2006.886600.

[3] D. Janik, T. Kosan, M. Zeman, L. Streit and Z. Peroutka, "Active voltage balancing control with phase disposition PWM for 4-level flying capacitor converter," 2013 15th European Conference on Power Electronics and Applications (EPE), Lille, France, 2013, pp. 1-8, doi: 10.1109/EPE.2013.6634604.

[4] M. M. da Silva and H. Pinheiro, "Voltage balancing in flying capacitor converter multilevel using space vector modulation," 2017 IEEE 8th International Symposium on Power Electronics for Distributed Generation Systems (PEDG), Florianopolis, 2017, pp. 1-5, doi: 10.1109/PEDG.2017.7972477.

[5] E. I. Silva, B. P. McGrath, D. E. Quevedo and G. C. Goodwin, "Predictive Control of a Flying Capacitor Converter," 2007 American Control Conference, New York, NY, USA, 2007, pp. 3763-3768, doi: 10.1109/ACC.2007.4282860

[6] P. Ponnambalam, M. Praveenkumar, J. B. Edward, J. G. Shankar, G. Gokulakrishnan and K. Aroul, "Comparison of Fuzzy and MPC based Flying Capacitor Multicell Inverter," 2016 IEEE Region 10 Conference (TENCON), Singapore, 2016, pp. 70-76, doi: 10.1109/TENCON.2016.7847961. 